\title{
Correlation between functionality, mobility and risk of falls in elderly people with Alzheimer's disease
}

\section{Correlação entre funcionalidade, mobilidade e risco de quedas em idosos com doença de Alzheimer}

\author{
Hudson Azevedo Pinheiro \\ (D) https://orcid.org/0000-0003-1081-4174 \\ Jaquelynne Dourado Mendes Brandão² \\ (D) https://orcid.org/0000-0002-3541-6669 \\ Aline Laginestra e Silva ${ }^{1,3}$ \\ (D) https://orcid.org/0000-0001-6810-4293
}

\begin{abstract}
To evaluate functional capacity, mobility and balance in elderly patients with Alzheimer's Disease (AD), in its mild, moderate and severe forms, verifying the existence of correlation among these parameters. Eighty-eight elderly patients (81.79 \pm 6.54 years) diagnosed with $\mathrm{AD}$ treated at an elderly care reference center in Taguatinga-DF were selected, and information was collected between November 2018 and March 2019. Data collection was initially made by filling in the evaluation form. Subsequently, two questionnaires were administered to caregivers (Clinical Dementia Rating-CDR and Disability Assessment for Dementia-DAD) and two tests to demented patients (Southampton Assessment of MobilitySAM-Br and Timed Up and Go-TUG). Variables were correlated using the SPSS software version 22 using Pearson's correlation, with significance level $p \leq 0.05$. The following results were obtained: 1 . weak correlations between CDR and DAD ( $p=0.04 ; r=-0.31)$ with significant difference; 2. strong correlation and significant difference between CDR and TUG ( $p=0.02$; $\mathrm{r}=0.87) ; 3$. weak and non-significant correlation between CDR and SAM-Br $(\mathrm{p}=0.14 ; \mathrm{r}=$ $-0.24) ; 4$. significant difference and highly strong correlation between SAM-Br and TUG ( $\mathrm{p}$ $=0.01 ; \mathrm{r}=0.70$ ). Older adults with Alzheimer's disease present decreased functional capacity, mobility and risk of falls associated with the disease progression. SAM-Br and TUG tools showed strong correlation and, although it is a generic measure, TUG showed strong correlation with $\mathrm{AD}$ progression, and may be a predictive test for the risk of falls in this population.

Key words: Alzheimer disease; Mobility limitation; Postural balance.
\end{abstract}

Resumo - Avaliar a capacidade funcional, mobilidade e equilíbrio em pacientes idosos com Doença de Alzheimer (DA). Foram selecionados 88 pacientes idosos (81,79 $\pm 6,54$ anos) diagnosticados com $D A$ atendidos em um centro de referência atendimento a idosos, e estas informaçôes foram coletadas entre janeiro e junho de 2019, com o preenchimento da ficha de avaliação. A seguir, aplicaram-se dois questionários aos cuidadores (Clinical Dementia Rating-CDR e Disability Assessment for Dementia -DAD) e dois testes aos idosos dementados (Southampton Assessment of Mobility-SAM-Br e Timed Get Up and Go-TUG). A correlação das variáveis foi feita no software SPSS versão 22 com o uso da Correlação de Pearson, considerando-se o nível de significância $p \leq 0,05$. Obtiveram-se correlações fracas entre $C D R$ e $D A D(p=0,04 ; r=-0,31)$ com diferença significativa; correlação forte e diferença significativa entre $C D R$ e $T U G(p=0,02 ; r=0,87) ; C D R$ teve correlação fraca e não significativa com $S A M-B r(p=0,14 ; r=-0,24)$; diferença significativa e correlaçẫo altamente forte entre $S A M-B r$ e TUG $(p=0,01 ; r=0,70)$. Os idosos com doença de Alzheimer apresentam diminuição da capacidade funcional, mobilidade e risco de quedas associada ao avanço da doença. As ferramentas SAM-Bre TUG apresentaram correlação forte estre elas e, apesar de ser uma medida genérica, o TUG apresentou forte correlação com o avanço da $\mathrm{DA}$, podendo ser um teste preditivo para o risco de quedas nesta população.

Palavras-chave: Doença de Alzheimer; Equilíbrio postural; Limitaçấo da mobilidade.
1 Federal District Health Department. Geriatrics and Gerontology Outpatient Clinic. Brasilia DF. Brazil

2 'EuroAmericano’ University Center of Brasília. Physiotherapy course. Brasilia DF. Brazil

3 Catholic University of Brasília. Medical course. Brasilia DF. Brazil

Received: November 25, 2019 Accepted: April 17, 2020

How to cite this article Pinheiro HA, Brandão JDM, Laginestra, AS. Correlation between functionality, mobility and risk of falls in elderly people with Alzheimer's disease. Rev Bras Cineantropom Desempenho Hum 2020, 22:e70219. D0l: http://dx.doi. org/10.1590/1980-0037.2020v22e70219

Copyright: This work is licensed under a Creative Commons Attribution 4.0 International License. 


\section{INTRODUCTION}

During the natural aging process, declines are observed in the various body systems, including the central nervous system, with neuronal loss and decreased synthesis of neurotransmitters, which causes changes in postural control and balance and cognitive decline involving judgment, calculation, visual-spatial skills and recent memory, increasing the risk of falls ${ }^{1-3}$.

The decline in functional capacity is related to the inability or difficulty of performing basic or more complex physical tasks, necessary for independent living resulting from the interaction between physical and mental health, independence in daily life, social integration, family support and economic independence 4 .

Dementias are understood as a tripod of changes: cognitive, behavioral and impairment in activities of the daily living (ADL), the most frequent being Alzheimer's Disease (AD), which contributes to about $60 \%$ to $70 \%$ of cases. It is estimated that the number of people with dementia will reach 65.7 million in 2030 and 115.4 million in 2050, which is a global health concern for governments and policy makers ${ }^{5,6}$.

Cognitive decline due to $\mathrm{AD}$ is closely related to the loss of the ability to perform instrumental activities of the daily living (IADL) and, later, basic activities of the daily living (BADL), leading the individual to the sequential loss of autonomy, making him / her submissive to the care and supervision of others, whether formal or informal caregivers ${ }^{7,8}$.

The literature has shown that in mild stages of $\mathrm{AD}$, the risk of falls is comparable to that of healthy older adults; however, motor processes regulated by complex cortical mechanisms, such as sitting and getting up from the chair, may already be affected, predisposing them to falls and, in advanced stages, this risk is probably high as a result of visual impairment and cognitive changes, which also interfere with ADL9.

In this context, the present study aimed to evaluate functional capacity, mobility and balance in elderly patients with $\mathrm{AD}$, in its mild, moderate and severe forms, checking if there is correlation among these parameters.

\section{METHODS}

This is a cross-sectional study with convenience sample composed of elderly patients with $\mathrm{AD}$ with diagnosis being established by geriatric physicians who are part of the geriatric and gerontology outpatient clinic, TaguatingaDF, according to the diagnostic and statistical manual of mental diseases and ICD- 10 - International Classification of Diseases. The research was carried out between January and June 2019. The study was approved by the Ethics Research Committee of the Catholic University of Brasília under protocol 2.788.564.

Inclusion criteria for elderly people with $\mathrm{AD}$ in the sample were: residents in the community; to carry out at least home gait; presence of informal or formal caregiver, who establishes frequent contact with the 
patient. Exclusion criteria were: total mobility disability; causes of dementia other than AD; subjects from long-term care facilities for the elderly; other associated neurological disorders; and those who used orthoses and / or prostheses.

After signing the informed consent form, caregivers answered two questionnaires. Subsequently, patients were evaluated using a scale and a test, both in a single moment, performed by the main researcher, previously trained to apply these assessment instruments.

A form was used to record data (age, schooling, marital status and income), and to assess the stage of the disease, the Clinical Dementia Rating (CDR) validated in Brazil was used ${ }^{10}$.

The disability assessment for dementia (DAD-Br) scale was applied to the caregiver to determine the degree of functional independence for $\mathrm{BADL}$ and IADL in a percentage that the patient with dementia was able to perform without help or without being remembered by the caregiver in the last two weeks ${ }^{11}$.

For assessing mobility, the Southampton assessment for mobility (SAM-Br) was used, being a specific instrument for elderly people with dementia to estimate the risk of falls through four simple tasks: moving from sitting to standing, staying in foot, walk and moving from standing to sitting, validated and adapted in Brazi $1^{12}$.

To assess functional mobility and balance indirectly, the Timed Get Up and Go (TUG) test was used ${ }^{13}$. It measures, in seconds, the time spent by the individual to get up from a chair with arms, walk a distance of 3 meters, go around, walk towards the chair and sit again. Less than $10 \mathrm{sec}-$ onds corresponds to low risk, 10 to 20 seconds to medium risk and, above 20 seconds to high risk of falls ${ }^{14}$. Thus, if the individual does the journey in up to 20 seconds, he / she is considered to be within the normal range and independent in BADL.

The SPSS software version 22 was used for statistical analysis, and the Shapiro-Wilk test indicated that data were not normal, opting for nonparametric tests and, in the case of the present study, Pearson correlation tests were used, always taking into account significance level of $\mathrm{p} \leq 0.05$.

\section{RESULTS}

Eighty-eight elderly people living in the community participated in this study, all of whom had clinical diagnosis of AD, and information regarding their profile is described in table 1.

Table 2 shows the results of Spearman's correlation tests showing associations between tests used. There were statistically significant differences between CDR and DAD-Br and strong correlation between these tests, that is, disease staging and functionality.

There were no differences between disease staging and mobility and balance, although there was a tendency to point out difference between CRD and TUG $(\mathrm{p}=0.09)$. 
Table 1. Categorization of the sample of elderly people with AD

\begin{tabular}{lc}
\hline Sex & $\mathrm{N}(\%)$ \\
\hline Female & $28(31.1)$ \\
Male & $60(67.3)$ \\
Age (years) & Mean (SD) \\
81.7 & 6.54 \\
Schooling & $\%$ \\
\hline Illiterate & 16.3 \\
\hline Elementary School & 46.5 \\
High School & 25.6 \\
\hline Higher Education & 11.6 \\
\hline Functional Tests & $M e a n(S D)$ \\
CDR & $2.00 \pm 1.00$ \\
SAM-Br & $15.47 \pm 2.64$ \\
DAD-Br & $42.69 \pm 16.18$ \\
\hline TUG & $30.29 \pm 24.13$ \\
\hline
\end{tabular}

Note. $\mathrm{CDR}=$ Clinical Dementia Ratio; $\mathrm{SAM}-\mathrm{Br}=$ Southampton assessment for mobility; $\mathrm{DAD}-\mathrm{Br}=$ Disability Assessment for Dementia; TUG = Timed Get up and go.

Table 2. Correlation between disease staging tests and functional assessment in $A D$

\begin{tabular}{lcc}
\hline Tests & $p$ & $r$ \\
\hline CDR & 0.09 & 0.54 \\
TUG & & -0.69 \\
CDR & $0.0001^{*}$ & \\
DAD-Br & & -0.19 \\
CDR & 0.19 & \\
SAM-BR & & -0.70 \\
SAM-Br & $0.01^{* *}$ & \\
TUG & & \\
\hline
\end{tabular}

Note. ${ }^{*} \mathrm{p}<0.01 . \mathrm{CDR}=$ Clinical Dementia Ratio; $\mathrm{SAM}-\mathrm{Br}=$ Southampton assessment for mobility; $\mathrm{DAD}-\mathrm{Br}=$ Disability Assessment for Dementia; TUG = Timed Get up and go.

\section{DISCUSSION}

In the present study, association was observed between disease stage measured by CDR and increased risk of falls measured by both SAM-Br and TUG.

In the present study, functionality analyzed by DAD evaluated, in the last two weeks, which BADL and IADL the demented patient was able to perform without help or without being remembered by the caregiver. It was found that the more the level of AD severity increased, the more reduced the functional capacity. Such findings corroborate Santos and Lira, who found association between advancing cognitive impairment and reduced functional mobility, thus increasing the risk of falls ${ }^{15}$.

These results are also in agreement with Borges et al. ${ }^{8}$, who revealed decline in the ability to perform functional activities as a result of the clinical evolution of the disease, reporting that cognitive impairment interfered with functions such as planning and the actual motor execution of the activity and with Zidan et al. ${ }^{3}$, who reported that independence in 
BADL and IADL was significantly lower as AD symptoms worsened, with the best performance obtained in group with mild AD (CDR1). This author also found that the loss of independence was greater than the physical and cognitive decline objectively assessed in moderate and severe stages of $\mathrm{AD}^{8,3}$.

Regarding the level of balance and propensity to fall, time in the TUG test greater than 30 seconds indicates that the subject has high tendency to fall ${ }^{16,17}$. In the current research, it was found that the TUG test had mean value above the cutoff point, which is recommended as the risk of falls in the elderly, with strong correlation.

Although SAM-Br is a specific scale to be used in elderly patients with dementia, TUG showed strong correlation with it, and it can be used as an important tool for the evaluation of elderly patients with dementia.

Berry et al. ${ }^{18}$, carried out a systematic review on the TUG test as a tool for predicting falls, since the present test was developed to assess functional mobility, and concluded that the TUG test needs a test or tool that can revalidate it to indicate this risk of falls, and as cognitive decline as an intrinsic risk factor is well established in literature, the TUG test can be applied for this purpose ${ }^{18}$.

In a study with fragile elderly people without cognitive decline, Clegg et al. ${ }^{19}$, used TUG as an indirect tool to estimate muscle strength to stratify training volume and training levels in physiotherapy sessions, demonstrating a new potential for this test, which could be extrapolated to the elderly population with $\mathrm{AD}^{19}$.

Significant correlation was observed between high results in SAM-Br and low in TUG. The mean value in SAM-Br can be explained by the fact that the majority of individuals in the sample had moderate degree of AD and the lower the degree of the disease, the greater the individual's mobility. Thus, individuals with AD in our sample still had good mobility. Data found here are in agreement with those of Woellner et al. ${ }^{20}$, who studied 20 elderly patients and concluded that long time in TUG performance the low score on the Performance Oriented Mobility Assessment (POMA), a test used to assess functional mobility, indicate functional mobility with decreased performance in patients with $\mathrm{AD}$, that is, there is greater predisposition to falls in those with increased score on the TUG test and decreased on the POMA test ${ }^{20}$.

However, the current study revealed that, when comparing balance and propensity to fall (TUG) and mobility (SAM-Br) tests, TUG proved to be much more sensitive than SAM-Br.

One of the limitations of this study was the number of elderly patients with $\mathrm{AD}$ assessed. A significant number of individuals were invited to participate in the study, but did not attend assessments with their caregivers (formal or informal) due to difficulties in moving from their homes to the place where the research took place.

In the present study, the types of medication used by patients in the sample were also not evaluated, and whether they could interfere with the 
functional capacity, mobility and risk of falling or even the fear of falling, as well as issues related to regular physical exercise (dose, intensity) that could influence such results. It is suggested that in further studies, such variables are considered.

\section{CONCLUSION}

Elderly patients with Alzheimer's disease have decreased functional capacity, mobility and risk of falls associated with the disease progression. SAM-Br and TUG tools showed strong correlation with each other, and despite being a generic measure, TUG showed strong correlation with the advancement of AD, which can be a predictive test for the risk of falls in this population.

\section{COMPLIANCE WITH ETHICAL STANDARDS}

\section{Funding}

Jaquelynne Dourado Mendes Brandão received scholarship of the FAPDF

\section{Ethical approval}

Ethical approval was obtained from the local Human Research Ethics Committee -Universidade Católica de Brasília and the protocol (no. 2.788.564) was written in accordance with the standards set by the Declaration of Helsinki.

\section{Conflict of interest statement}

The authors have no conflict of interests to declare.

\section{Author Contributions}

Conceived and designed the experiments: HAP, JDMB. Performed the experiments: HAP, ASL. Analyzed the data: HAP. Contributed reagents/ materials/analysis tools: HAP, ASL. Wrote the paper: HAP.

\section{REFERENCES}

1. Valcarenghi RV, Santos SSC, Barlem ELD, Pelzer MT, Gomes GC, Lange C. Alterações na funcionalidade/cognição e depressão em idosos institucionalizados que sofreram quedas. Acta Paul Enferm 2011;24(6):828-33.

2. Aragão FA. Influências do envelhecimento, do tempo de evolução da doença e do estado cognitivo sobre os episódios de quedas, em uma população parkinsoniana. Fisioter Bras 2018;6(4):250-4.

3. Zidan M, Arcoverde C, Araújo NB de, Vasques P, Rios A, Laks J, et al. Motor and functional changes in different stages of Alzheimer's disease. Arch Clin Psychiatry (São Paulo) 2012;39(5):161-5.

4. Gratão ACM, da Silva Talmelli LF, Figueiredo LC, Rosset I, Freitas CP, Rodrigues RAP. Dependência funcional de idosos e a sobrecarga do cuidador. Rev Esc Enferm USP 2013;47(1):137-44.

5. Takizawa C, Thompson PL, van Walsem A, Faure C, Maier WC. Epidemiological and economic burden of Alzheimer's disease: a systematic literature review 
of data across Europe and the United States of America. J Alzheimer's Dis 2015;43(4):1271-84.

6. Savva GM, Brayne C. Epidemiología y repercusión de la demencia. In: Weiner MF, Lipton AM, editors. Manual de Enfermedad de Alzheimer y otras demencias. Madrid: Editorial Panamericana; 2010. p. 17-21.

7. Arcoverde C, Deslandes A, Rangel A, Rangel A, Pavão R, Nigri F, et al. Role of physical activity on the maintenance of cognition and activities of daily living in elderly with Alzheimer's disease. Arq Neuropsiquiatr 2008;66(2 B):323-7.

8. Borges LL, Albuquerque CR, Garcia PA. The impact of cognitive, functional, and mobility decline of elderly with Alzheimer disease on their caregivers' burden. Fisioter Pesqui 2009;16(3):246-51.

9. Ferreira LL, Sanches GGA, Marcondes LP, Saad PCB. Risco de queda em idosos institucionalizados com doença de Alzheimer. Rev Kairós Gerontol 2013;16(3):95-105.

10. Bahia VS, Carthery-Goulart MT, Novelli MM, Kato-Narita EM, Areza-Fegyveres $\mathrm{R}$, Caramelli P, et al. Functional disability in Alzheimer disease: a validation study of the Brazilian version of the Disability Assessment for Dementia (DADBr). Alzheimer Dis Assoc Disord 2010;24(3):291-5.

11. Carthery-Goulart MT, Areza-Fegyveres R, Schultz RR, Okamoto I, Caramelli P, Bertolucci PHF, et al. Adaptação transcultural da escala de avaliação de incapacidade em demência (disability assessment for dementia - DAD). Arq Neuropsiquiatr 2007;65(3 B):916-9.

12. Pereira LSM, Marra TA, Faria CDC de M, Pereira DS, Martins MAA, Dias JMD, et al. Adaptação transcultural e análise da confiabilidade do Southampton Assessment of Mobility para avaliar a mobilidade de idosos brasileiros com demência. Cad Saude Publica 2006;22:2085-95.

13. Podsiadlo D, Richardson S. The timed "up \& go": A test of basic functional mobility for frail elderly persons. J Am Geriatr Soc 1991;39(2):142-8.

14. Carvalho GA, Peixoto NM, Capella PD De. Análise comparativa da avaliação funcional do paciente geriátrico institucionalizado por meio dos protocolos de Katz e Tinetti. 2007;1-8.

15. Santos LCS, Lira M. Correlação entre função cognitiva e capacidade funcional nos indivíduos com doença de Alzheimer. Cad Pósgrad Distúrbios Desenvolv 2012;12(2):36-45.

16. Podsiadlo D, Richardson S. The timed “Up \& Go": a test of basic functional mobility for frail elderly persons. J Am Geriatr Soc 1991;39(2):142-8.

17. Silva TBL, Yassuda MS, Guimarães VV, Florindo AA. Fluência verbal e variáveis sociodemográficas no processo de envelhecimento: um estudo epidemiológico. Psicol Reflex Crit 2011;24(4):739-46.

18. Barry E, Galvin R, Keogh C, Horgan F, Fahey T. Is the Timed Up and Go test a useful predictor of risk of falls in community dwelling older adults: A systematic review and meta- analysis. BMC Geriatr 2014;14(1).

19. Clegg A, Barber S, Young J, Iliffe S, Forster A. The Home-based Older People's Exercise (HOPE) trial: A pilot randomised controlled trial of a home-based exercise intervention for older people with frailty. Age Ageing 2014;43(5):687-95.

20. Woellner SS, Araújo AG dos S, Risso PR, Hoepfer Jr H. Estudo comparativo da mobilidade orientada pelo desempenho em idosos com e sem doença de Alzheimer. Rev Bras Med 2012;69(11):1-5.

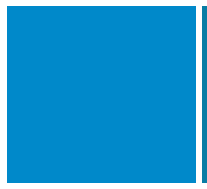

Corresponding author

Hudson Azevedo Pinheiro

Rua 36 norte, Bloco 05, apartamento 401, Águas Claras, Brasília-DF, Brasil.

Zip postal: 71919-180

Email: hudsonap@gmail.com 